\title{
Determining the Source of Water Vapor in a Cerium Oxide Electrochemical Oxygen Separator to Achieve Aviator Grade Oxygen.
}

\author{
John Graf ${ }^{1}$, Dale Taylor ${ }^{2}$ and James Martinez ${ }^{3}$ \\ 1. Crew and Thermal Systems Division, NASA-Johnson Space Center, Houston TX, USA. \\ 2. Engineering Department, Ceramatec, Salt Lake City UT, USA. \\ 3. Structural Engineering Division, NASA-Johnson Space Center, Houston TX, USA.
}

More than a metric ton of water is transported to the International Space Station (ISS) each year to provide breathing oxygen for the astronauts. Water is a safe and compact form of stored oxygen. The water is electrolyzed on ISS and ambient pressure oxygen is delivered to the cabin. A much smaller amount of oxygen is used each year in spacesuits to conduct Extra Vehicular Activities (EVAs). Space suits need high pressure (>1000 psia) high purity oxygen (must meet Aviator Breathing Oxygen "ABO" specifications, $>99.5 \% \mathrm{O}_{2}$ ). The water / water electrolysis system cannot directly provide high pressure, high purity oxygen, so oxygen for EVAs is transported to ISS in high pressure gas tanks. The tanks are relatively large and heavy, and the majority of the system launch weight is for the tanks and not the oxygen. Extracting high purity oxygen from cabin air and mechanically compressing the oxygen might enable on-board production of EVA grade oxygen using the existing water / water electrolysis system. This capability might also benefit human spaceflight missions, where oxygen for EVAs could be stored in the form of water, and converted into high pressure oxygen on-demand.

Cerium oxide solid electrolyte-based ion transport membranes have been shown to separate oxygen from air, and a supported monolithic wafer form of the $\mathrm{C}_{\mathrm{e}} \mathrm{O}_{2}$ electrolyte membrane has been shown to deliver oxygen at pressures greater than 300 psia. These supported monolithic wafers can withstand high pressure differentials even though the membrane is very thin, because the ion transport membrane is supported on both sides (Fig 1). The monolithic supported wafers have six distinct layers, each with matched coefficients of thermal expansion. The wafers are assembled into a cell stack which allows easy air flow across the wafers, uniform current distribution, and uniform current density (Fig 2). The oxygen separation is reported to be "infinitely selective" to oxygen [1] with reported purity of 99.99\% [2]. Combined with a mechanical compressor, a Solid Electrolyte Oxygen Separator (SEOS) should be capable of producing $\mathrm{ABO}$ grade oxygen at pressures $>2400$ psia, on the space station.

Feasibility tests using a SEOS integrated with a mechanical compressor identified an unexpected contaminant in the oxygen: water vapour was found in the oxygen product, sometimes at concentrations higher than $40 \mathrm{ppm}$ (the $\mathrm{ABO}$ limit for water vapour is $7 \mathrm{ppm}$ ). If solid electrolyte membranes are really "infinitely selective" to oxygen as they are reported to be, where did the water come from? If water is getting into the oxygen, what other contaminants might get into the oxygen?

Microscopic analyses of wafers, welds, and oxygen delivery tubes were performed in an attempt to find the source of the water vapour contamination. Hot and cold pressure decay tests were performed. Measurements of water vapour as a function of $\mathrm{O}_{2}$ delivery rate, $\mathrm{O}_{2}$ delivery pressure, and process air humidity levels were the most instructive in finding the source of water contamination (Fig 3). Water contamination was directly affected by oxygen delivery rate (doubling the oxygen production rate cut the water level in half). Water was affected by process air humidity levels and delivery pressure in a way that indicates the water was diffusing into the oxygen delivery system. Test results shown in figure 
3 suggest that the ion transport membrane does not let any water vapour into the oxygen, but moisture is diffusing through the hot (500-750 degrees C) glass seals that contain the oxygen between the wafers in the cell stack. Water vapour permeation rates are consistent with those reported in the literature [3].

\section{References:}

[1] D Meixner et al, Journal of the Electrochemical Society, 149 (9) D132-D136 (2002)

[2] D Studor Air Force Research Lab Report AFRL-RH-BR-TR-2010-0046.

[3] M Manohar, International Journal of Modern Engineering Research, Vol 2 (4) pp 1492-1506. 2012.
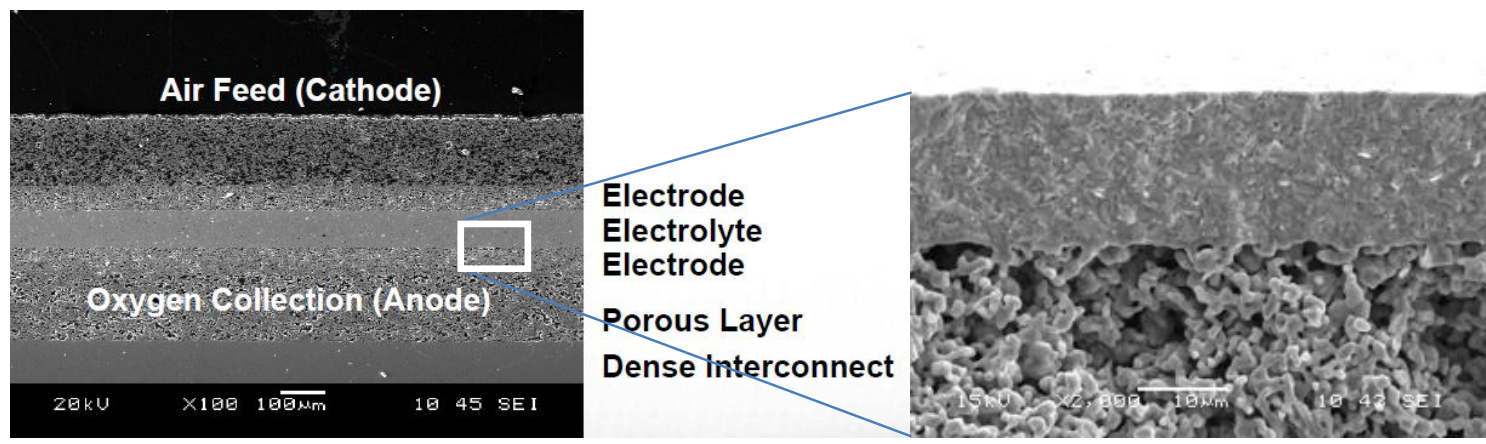

Figure 1. Supported Monolith SEOS Wafer in cross section
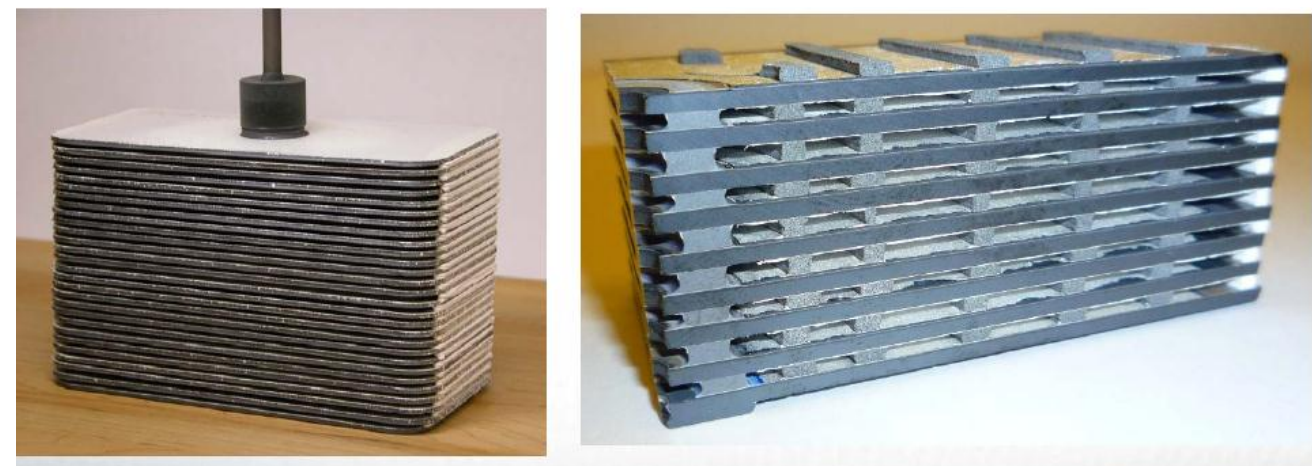

Figure 2. Photos of the cell stack, and a cut section of a cell stack (note glass seal in section view)

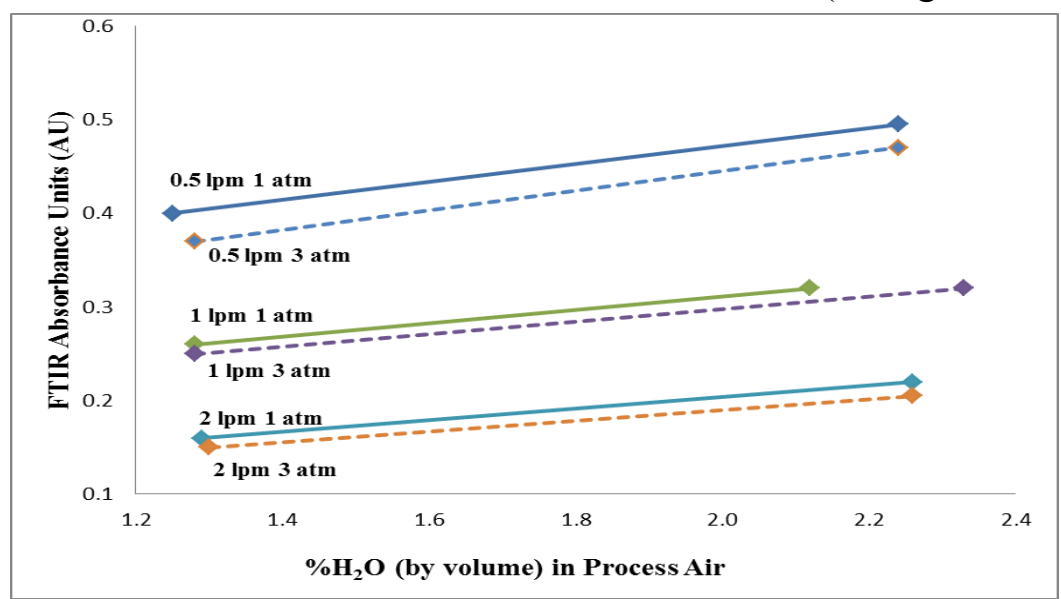

Figure 3. Plot of water contamination in oxygen, as a function of pressure, rate, and ambient humidity 